\title{
Reversibility of Endothelial Dysfunction Induced by Low Frequency of Electromagnetic Field in Patients with Diabetes Mellitus in Dialysis Extracorporeal
}

\section{Liani $\mathbf{M}^{1}$, Cacciagrano $\mathrm{MR}^{2}$, Di Luzio $\mathrm{R}^{2}$, Amelio $\mathrm{R}^{3}$, Velussi $\mathrm{C}^{4}$ and Liani $\mathbf{R}^{5}$}

${ }^{1}$ Former Director Nephrology and Dialysis, P.O. "S. Massimo", Penne (PE) AUSL

Pescara, Italy

${ }^{2}$ Department Health, "S. Massimo” Hospital, Penne, PE, Italy

${ }^{3}$ General Medicine Physician Taverna, Italy

${ }^{4}$ Retired Associate Professor of Physiology, Padua University, Italy

${ }^{5}$ Department of Medicine and Aging, and Center of Aging Science and Translational Medicine (CESI-Met), Via Colle dell'Ara, Chieti, 66013, Italy

*Corresponding author: Mario Liani, Former Director Nephrology and Dialysis, P.O. "St. Maximus", Penne (PE) AUSL Pescara, via Manzoni, 9 - 66020 San Giovanni Teatino (Chieti), Italy, Tel: 3337312253; Email: mario.liani@tin.it

\section{Abstract}

Aims: The life expectancy of patients with Type II Diabetes Mellitus (T2DM) and Diabetic Foot Syndrome (DFS) is dramatically short. The micro-angiopathy, in relation to endothelium dysfunction, decisively affects the vascular prognosis, perhaps more than macro-angiopathy. Increased availability of nitric oxide (NO) can cause numerous and predictable positive effects in relation to the different mechanisms of macro and micro vascular disease.

Methods: We measured NO blood in a group of patients with T2DM on dialysis before and after a Pulsating Electromagnetic Fields (PEMF) cycle and we tested, meanwhile, the reaction of surface receptor platelets GPIb and GPIIb/IIIa.

Results: The magnetic field causes an increase in the level of NO, probably due to a prolonged period of exposure, and a modification in the percentage of platelets type and causes a normalisation of the platelets surface receptors in renal patients in dialysis with T2DM.

Conclusions: The physical source, although, further investigation is required, can be instrumental in contributing to help with the complications of vascular macro and microcirculation. In our case the increase of NO had caused important

Reversibility of Endothelial Dysfunction Induced by Low Frequency of Electromagnetic

Field in Patients with Diabetes Mellitus in Dialysis Extracorporeal

Med J Clin Trials Case Stud 


\section{Medical Journal of Clinical Trials \& Case Studies}

effects on haemostasis that can't be ignored, knowing their role within the pathology of vascular diseases. The antithrombotic drugs prevent acute occlusion of the vessels but do not improve the status of endothelium dysfunction. Antithrombotic drugs prevent acute events but do not improve the related phenomena with poor function of the endothelium. Early tissue aging is a chronic and correlated process with microcirculation and endothelial dysfunction. In our case there is reasonable evidence that it is possible to induce functional improvements of the endothelium in chronic patients characterized by impaired endothelium function.

Keywords: Diabetes; Hemodialysis; Nitric Oxide; Endothelial dysfunction

Abbreviation: PEMF: Pulsed Electromagnetic Field; PESF: Pulsed Electrostatic Field; T2DM: Type 2 Diabetes Mellitus; NO: Nitric oxide; DFS: Diabetic Foot Syndrome; GPIb: Glycoprotein Ib; GPIIb/IIIa: Glycoprotein IIb/IIIa; HB Patients with diabetes mellitus in dialysis extracorporeal; CKD: Chronic Kidney Disease.

\section{Introduction}

The survival of patients affected with Type 2 Diabetes Mellitus (T2DM) Diabetic Foot Syndrome (DFS), after major amputation, isn't different from those who have contracted a malignant disease [1]. The continued spread of T2DM, it becomes an epidemic, caused an increased incidence of vascular complications, morbidity and especially mortality [2]. In Italy, every year, 27 thousand patients with T2DM die while in Europe 271000 despite the massive resources invested in this medical field $[3,4]$. Patients on hemodialysis therapy with T2DM have a cardiovascular prognosis significantly worse than their peers without kidney disease [5,6]. Macroangiopathy, which is frequently due to ischemia, is a dreaded complication among patients with T2DM [7]. Instead, microangiopathy, which does not play in the thinking of many fundamental role, is asymptomatic and conditioning, in quality and quantity perfusion and nutrition reducing tissue mass. In addition, microangiopathy reduces the effectiveness of drugs and affects vascular prognosis. The altered biosynthetic capacity of the endothelium, dysfunctional endothelial, proves to be at the origin of most of the pathogenic mechanisms involved in the processes of vascular disease of the peripheral circulation [8,9].

The dialysis treatment causes an acceptable recovery, but does not completely eliminate all uremic toxins, does not restore normal endothelial activities and does not modify the inflammation, oxidative stress, insulin resistance and vascular calcification [9,10]. Recent

Liani M, et al. Reversibility of Endothelial Dysfunction Induced by Low Frequency of Electromagnetic Field in Patients with Diabetes Mellitus in Dialysis Extracorporeal. Med J Clin Trials Case Stud 2018, 2(5): 000175. research has found that the endothelial dysfunction, in case of inflammation, compromises the correct permeability of micro circulatory systems, and the correct ratio of exchange with tissue $[11,12]$.

It seems clear that to get the reversibility of dysfunctional endothelium is objectively a priority and that only a function of the endothelium could best improve performance micro and macro-vascular diseases. So far, however, they are not available in routine clinical therapies with proven efficacy on endothelial dysfunction.

The exposure, in vitro, of endothelial cells, osteoblasts or cells of other tissues to pulsed electromagnetic fields (Pulsating Electromagnetic Fields, PEMF - 60-75 Hz) at low frequency, as the exposure to pulsed electrostatic fields [Electrostatic Pulsating Field - PESF), see Table 1, causes changes in intracellular calcium levels and causes a change of enzymatic activity of nitric oxide synthase with increase in nitric oxide (NO) within the cells themselves [13].

\begin{tabular}{|c|c|}
\hline $\begin{array}{c}\text { Pulsating Magnetic Field } \\
\text { (PEMF) }\end{array}$ & $\begin{array}{c}\text { Pulsating Electrostatic } \\
\text { Field (PESF) }\end{array}$ \\
\hline $\begin{array}{c}\text { The infinitely small } \\
\text { electric current causes a } \\
\text { charge within the subject } \\
\text { matter creating motion }\end{array}$ & $\begin{array}{c}\text { The charge creates both a } \\
\text { positive and negative } \\
\text { reaction }\end{array}$ \\
\hline $\begin{array}{c}\text { The subject matter when } \\
\text { stimulated by the electric } \\
\text { current becomes } \\
\text { organized in its motion }\end{array}$ & $\begin{array}{c}\text { The subject matter is } \\
\text { represented as } \\
\text { distinguishable spikes }\end{array}$ \\
\hline $\begin{array}{c}\text { It isn't possible to } \\
\text { separate the two magnetic } \\
\text { fields }\end{array}$ & $\begin{array}{c}\text { It is possible to separate } \\
\text { the positive charge from } \\
\text { the negative }\end{array}$ \\
\hline
\end{tabular}

Table 1: Magnetic and Electrostatic Fields, reaction of subject matters when passed through the two fields. 


\section{Medical Journal of Clinical Trials \& Case Studies}

Still in vitro, when stimulated by PEMF or PESF, endothelial cells are layered on the bottom of the plate, forming tubules form (first stage of angiogenesis) and release PGF-2 responsible for the growth of fibroblasts; osteoblasts proliferate and release NO and human keratinocytes (HaCaT) activates cyclo-oxygenase-2 $\left(\mathrm{COX}_{2}\right)[14,16]$. In experimental animals, the reversibility of endothelial dysfunction, documented an increase of NO, was associated with an improvement of the disease [17]. In the renal patient with diabetes mellitus, kidney being a highly vascularized organ is strongly influenced by microangiopathy and probably an increase in nitric oxide could result in a useful protection of the kidney [18].

In vivo, the physical source increases calcium in the bones of women with osteoporosis, accelerates consolidation of fractures of the bones, inducing increased base level metabolism, and contributes to accelerating the healing of serious wounds [19-23].

Similar results suggest that the use of physical sources in clinic is possible, and as in the healing of wounds, the effect that they cause is interesting if you accept the existence of a correlation between endothelial cells, physical stimuli and microcirculation [24,25].

Some results show that also in renal illnesses with T2DM and non-dialysis the endothelial dysfunction can be improved [26].

Since it is clear that a greater availability of nitric oxide (NO) can produce numerous expected positive effects including improving vasoconstriction, normalizing platelet aggregation, reducing the proliferation and migration of smooth muscle cells, reducing adhesion of platelet and leukocytes we have measured NO blood in a group of patients with T2DM on dialysis before and after a cycle of PEMF [27]. Also, to determine that a higher level of NO produces positive biological effects, we have valued the platelet surface receptors GPIb and GPIIb/IIIa.

\section{Methods}

We have selected 50 chronic kidney disease patients with T2DM in hemodialysis (HB). We have excluded patients with genetic predisposition to vascular disease, congenital diseases of the metabolism, haemostasis primitive disease, smoking or use of drugs for haemostasis, children and adults with peace makers, medical devices such as removable electrocardiographs, persons with acute diseases, malignancies (Malignant tumors), symptoms of infection, heart failure, fever or history of bleeding.

Participation in the study was voluntary and each had the opportunity to withdraw from the study at any time. Participants were assigned to group A or to group B, alternatively, in the order of acceptance. Finally, group A had 25 subjects, 12 females and 13 males, average age of $73.4 \pm 9.73$ years, in hemodialysis therapy for $37.17 \pm$ 28.26 months and had Kt/V $1.30 \pm 0.20$. Group B, which had also 25 patients, was composed of 14 males 11 females, average age of $72.77 \pm 9.67$ years, was in hemodialysis therapy for $38.68 \pm 27.65$ months and had $\mathrm{Kt} / \mathrm{V} 1.27 \pm 0.19$. Group A was to be treated with PEMF and group $\mathrm{B}$ was the control group. Within the groups we found there was a correlation between NO and the reaction of platelet surface receptors. Samples were performed on an empty stomach, the first day following a long inter-dialytic pause period (Monday or Tuesday). In this study we have used the electromagnetic field (PEMF).

The blood collection was performed without applying a tourniquet with a 19G needle and using Vacutainer with Citrate anticoagulant. To determine the expressiveness of the platelets surface receptors (GP1b and GPIIb/IIIa) through cytometry we have taken two blood samples of 100 microliters from each tube and to each was added respectively 10 microliters of monoclonal antibody $42 \mathrm{~b}$ the specific receptor for GPIb and 10 microliters of monoclonal antibody 41 the specific receptor for GPIIb/IIIa both of Immunotec. All tubes were agitated in the vortex after adding 90 microliters of PBS and incubated for 30 minutes at a dark room temperature. After incubation another quantity of 500 microliters of PBS was added to each tube and each was again placed in the vortex. Finally, reading where taken with the flow cytometry system. The antibodies monoclonal used respectively CD42b (IgG 1 mouse IOP42b Clone FITC) and CD 41a ( $\operatorname{IgG}_{1}$ Clone P2 FITC) from the company Immunotech (Marseille) were fluorescein. The reading was performed on a flow cytometric device type FACScan, BECTON- DICKINSON-USA that and was prepared, as per instructions, after proper calibration for logarithmic amplification of the FL 1 . Values are expressed in\% of mean flow compared to a reference standard and the luminescence of platelets in "mean flow".

Blood samples were collected before and after PESF cycle. We have assayed NO serum levels using a commercial kit ELISA (R\&D). We used the spectrophotometric assay (Greiss reaction) to determine blood NO levels. This is based on the enzymatic 


\section{Medical Journal of Clinical Trials \& Case Studies}

conversion of nitrate to nitrite by nitrate reductase. This type of reaction develops in two phases; in the first phase is a nitrogenation reaction in which $\mathrm{NO}_{2}$ in an acidified produces a nitrosant agent and in a second phase in which the reaction with sulfanilic acid produces the diazonium ion. This ion is then coupled to N-1-naphthyl) ethylenediamine to form a nitrogen derivate chromophore absorbing at 540-570 $\mathrm{nm}$ [27-29].

The significance between the average/mean of the group was determined by test 'Student 1 ' statistical analysis and logarithmic correlations. The field PEMF was administered with the MRT system or Bioresonance pulsed magnetic field generator. This has a number of technical peculiarities and is applicable in both preventive and therapeutic medicine. The system is equipped with a mat and a pillow for the locoregional treatment inside of which are inserted the solenoids which generate a particular and advanced Electromagnetic Field.

During treatment candidates are placed on the mat, are fully clothed, and are free to do whatever makes them feel comfortable, sitting or lying down and sleeping, reading, listening to music etc. The mat and the cushion are linked to a central governing system. The system is easy to use and the unit is small and can be easily transported and used at home. The type of emission generated by the electromagnetic wave is in the shape of saw tooth (Figure 1), the use of said waves allow us to obtain the best biological effects.

As represented in figure 1 the sawtooth wave consists of a cusp in positive phase followed by another in negative phase. The intensity of the magnetic field is very low $(50 \mu \mathrm{T}$ to that of the earth's magnetic field). This particular type of sawtooth wave allows us to make an important distinction from other types of waves such as square wave or the sine wave common in nearly all the systems in commercial use. The control unit modulates the delivery of PEMF automatically in order to make the administration as effective as possible. The type of wave is delivered evenly through the human body and causes an appreciable movement of ions, essential for biophysical effects.

The system acts on the bolts hydrogen (H hopping) that leads, in turn, to changes in the links between the negative charges exposed and the calcium often related to them. This event, known as "Waterfall of Calcium" causes biochemical effects. The stimulus induced with PEMF causes the breakdown of stacked red blood cells and a better delivery of $\mathrm{O}_{2}$ to tissues.

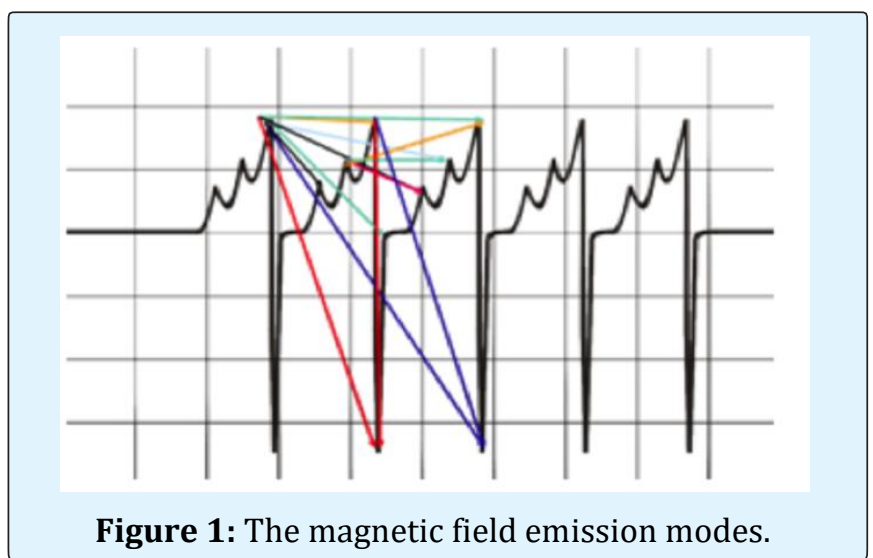

\section{Results}

It was only in the group treated with PEMF technology that there was a statistically significant base level increase of nitric oxide (Figure 2) and changes in surface receptors (Figure 3). In group B there was no variation in the base levels of NO and no changes in the reaction of the surface receptors of the platelets GPIb and GPIIb/IIIa (Table 2).

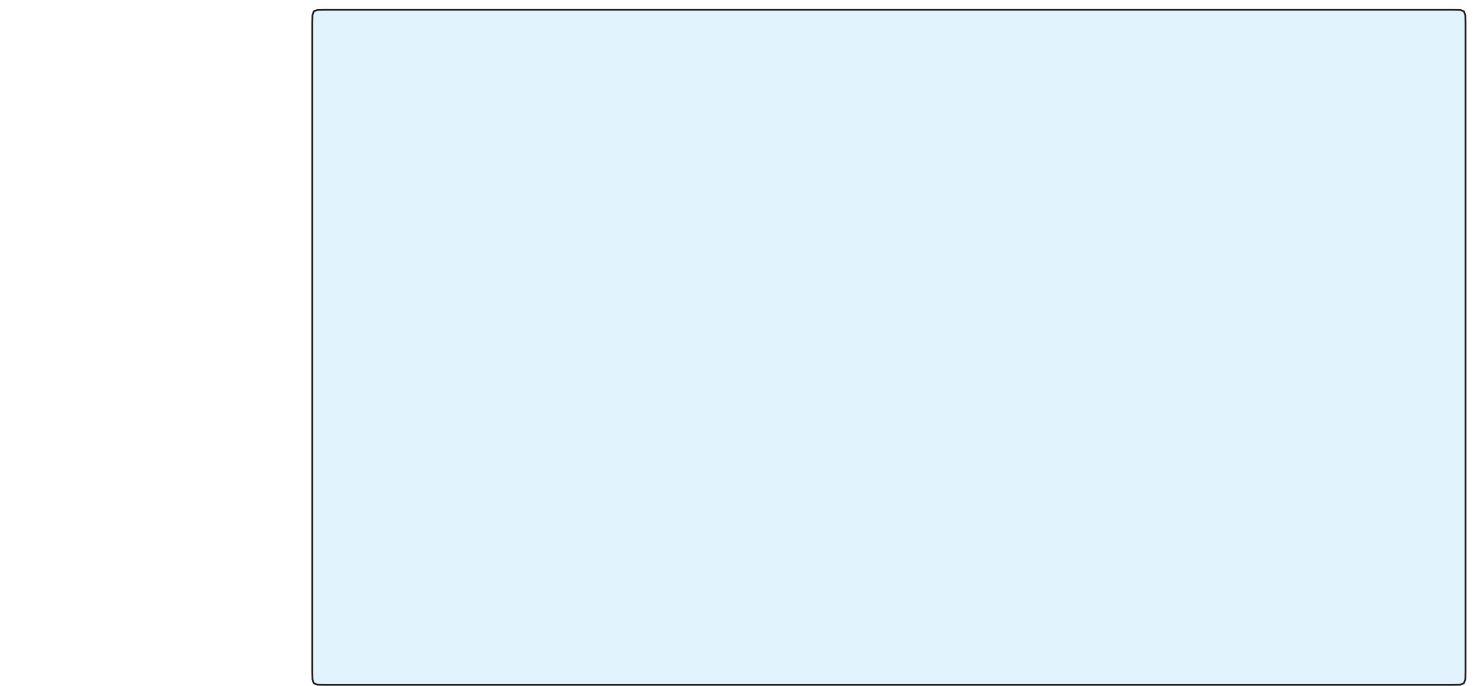

Liani M, et al. Reversibility of Endothelial Dysfunction Induced by Low Copyright@ Liani M, et al. Frequency of Electromagnetic Field in Patients with Diabetes Mellitus in Dialysis Extracorporeal. Med J Clin Trials Case Stud 2018, 2(5): 000175. 


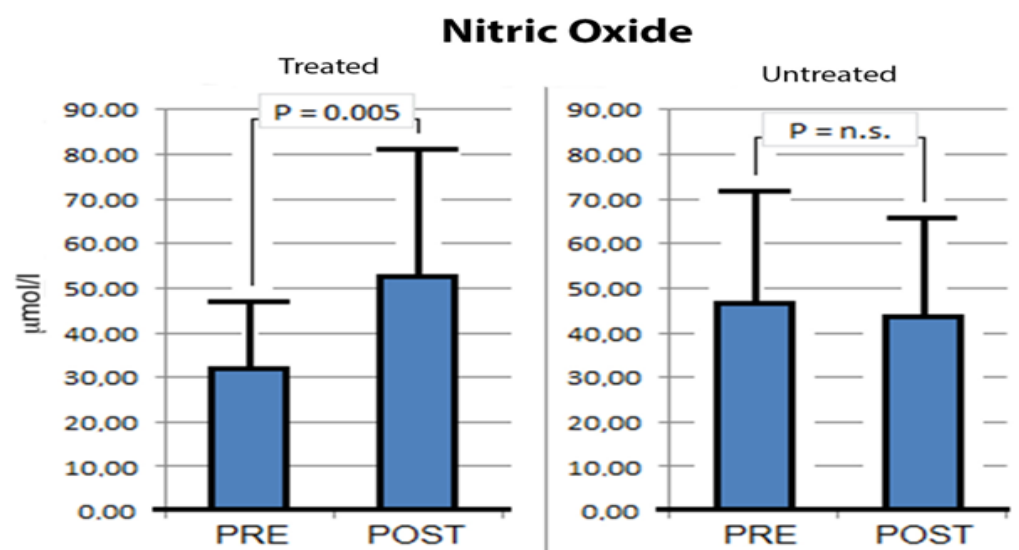

Figure 2: Levels of Nitric Oxide before and after PEMF cycle.

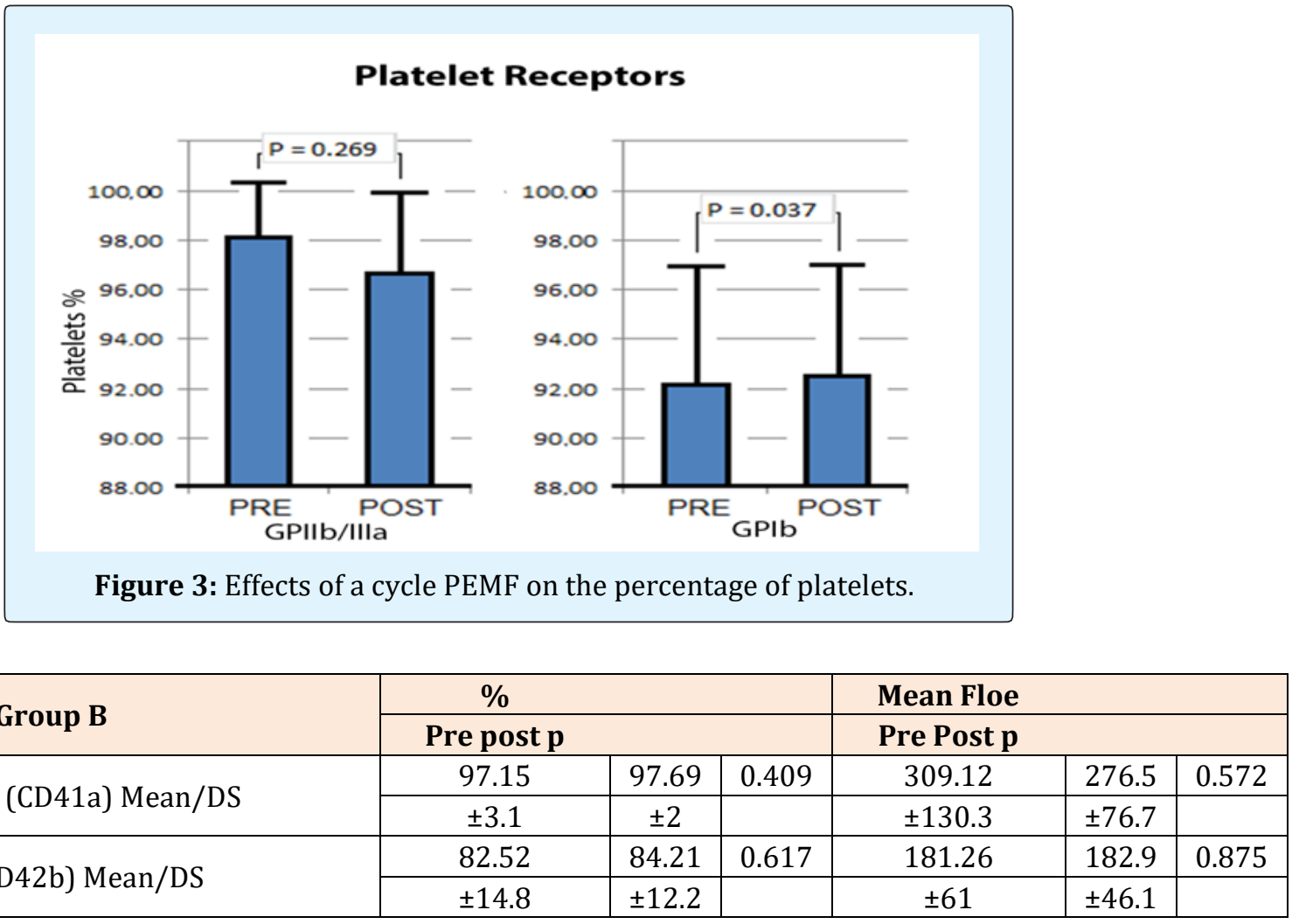

Table 2: Surface Platelets receptor, GPIIb/IIIb and GPIb, in Group B platelet receptors. 


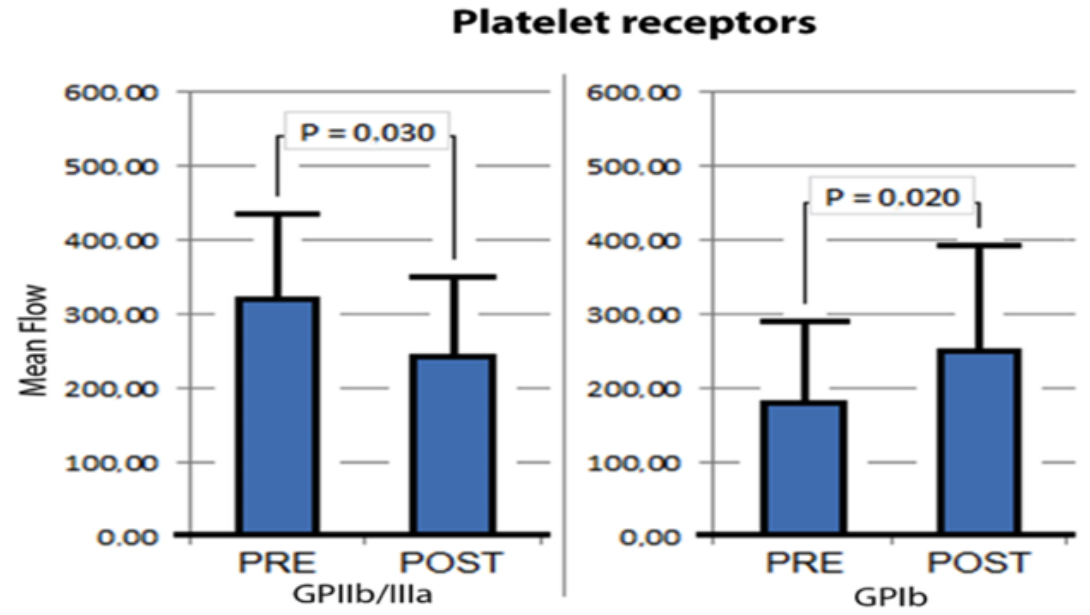

Figure 4: Effects of cycle PEMF on the Mean Flow of Platelets.

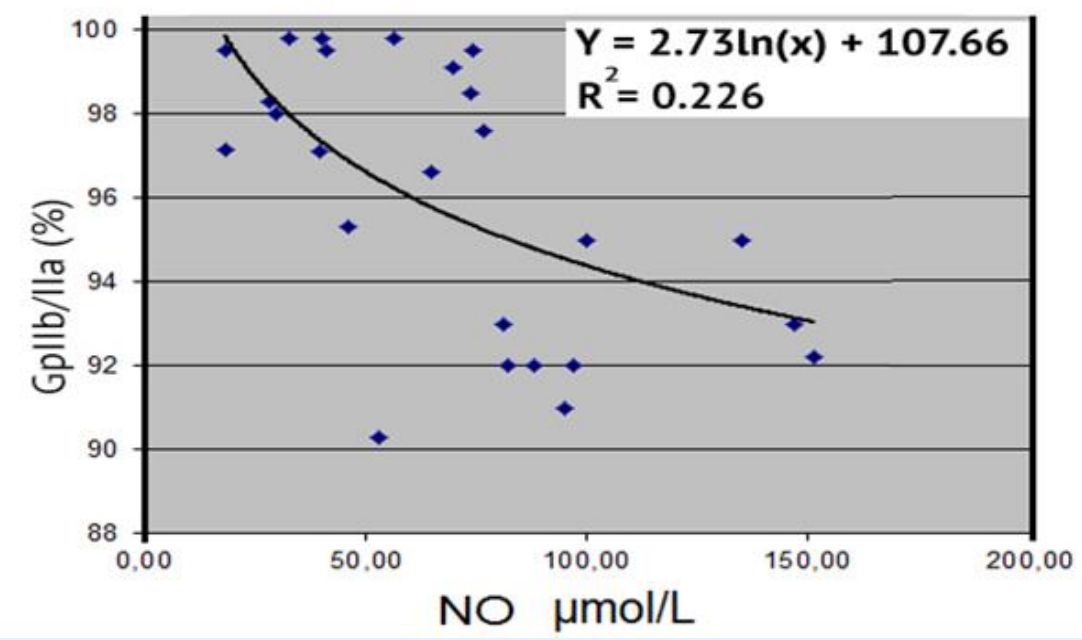

Figure 5: Inverse relationship between levels of No and GP IIb/IIa percentage (\%) at baseline.

In our experience with this group of renal patients, the technique PEMF induced a modest, but significant reduction in the percentage of platelets typed with the CD41a antibody (specific for receptor GpIIb/IIIa) but not that of platelets typed with the CD42b antibody (specific for receptor GPIb) (Figure 3). The technique PEMF did not change the reaction of surface receptors GPIIb/IIIa while, instead it created a significant increase in the receptor
GPIb. It should be remembered that, with the deterioration of kidney function, the activity of the receptor GPIIb/IIIa increases and the activity of the receptor GPIb is reduced.

\section{Discussion}




\section{Medical Journal of Clinical Trials \& Case Studies}

The exposure of endothelial cells and other cell lines to physical sources of low intensity induces an increase in biosynthetic enzymes, the release of active substances, proliferation, migration and the stratification of the cells in the culture medium. In case of osteoblasts the phenomenon stops beyond the threshold level which the synthesis of nitric oxide it becomes inhibited and potentially toxic to bone cells [13]. Our study was not undertaken with the aim of documenting the effects due to the inhibition although it seems to have emerged. It was undertaken with the sole purpose of verifying whether, in cases of illnesses with complications, there is the possibility of influencing the endothelial dysfunction. The increase of $\mathrm{NO}$ and the noting of certain phenomena correlated with NO, supports the idea that we can induce reversibility of endothelial dysfunction with physical sources.

Our study could be criticized because of the lack of a more stringent selection of patients in the two groups but this has the advantage of being a general cross-section of patients with many unknown factors not unlike that found in the general population. In our opinion, we have not modified any therapy already in use and still achieved a significant increase of NO, assuming that the physical can make a valid contribution when used in diseases with endothelial dysfunction and micro-circulatory pathology.

The increase in NO, that we have documented, seems to suggest that the physical sources, could play important role in prevention and have a relevant impact on budgets when you consider that those affected with T2DM in Italy and Europe represent the $8 \%$ and the $8.1 \%$ of the population, and those with impaired glucose tolerance (IGT) are 1.8 million and 33.5 million respectively. The direct and indirect costs amount to 20 and 188 billion euro each year $[3,4]$. The direct social costs, also including the healing of more difficult wounds, the more frequent and prolonged hospitalizations, reduced autonomy, the necessity of greater general nursing care, it should be added, in terminally ill, those requirements arising from the technical cleansing are generally more complex. A controlled increase of NO could have beneficial results.

The occurrence of localized infections (difficult ulcers) and amputations, large and small must be understood not only, as an extension of local ischemia in relation to macro-angiopathy but as a generalized pathology and a complexity of the impairment of microcirculation. Taking repeated drugs, prescribed in preventative medicine is not sufficient as they can have considerable side effects on general heath, repeated taking of a drug over a few years can be attributed to some cardio-vascular illnesses.
The use of acetyl salicylic acid, for instance, although administered for years, reduces thrombotic episodes but is not effective in preventing the compromise of vascular function. It can't be the only consolation that $16.9 \%$ of T2DM are totally, and $21.5 \%$ partly resistant to the protective effects of aspirin if adequate trials, when the same results were obtained from different groups, indicate that the intake of the drug does not give greater benefits in the treated group compared to the untreated [31-36].

The reduced effectiveness of aspirin (or aspirin resistance) suggests looking at more thoroughly. In a previous study we have shown that aspirin reduces platelet aggregation, but does not change the altered interaction between platelets and endothelium [34]. Any therapeutic operation disregards the altered interaction between platelets and damaged endothelium, and it is obvious that we may be able to modify the altered platelet-endothelium interaction if you act on endothelial cells. The healthy, intact and fully functioning endothelium, through NO, controls the aggregation and adhesion of blood cells and regulates the synthesis of nitric oxide that avoiding reaching toxic levels [13].

Our study was undertaken with the sole purpose of verifying whether, in cases of illnesses with complications, there is the possibility of influencing the endothelial dysfunction. The increase of $\mathrm{NO}$ and the noting of certain phenomena correlated with NO, supports the idea that we can induce reversibility of endothelial dysfunction with physical sources.

The increase in NO we documented seems to suggest that the physical sources could play important role in prevention and have a relevant impact on budgets when you consider those affected with T2DM $[3,4]$.

In our case, the physical source induced a modification in the ionic composition of the plasma, disaggregation of the red blood cells and FLOW motion, and it is difficult to not associate these effects with the improved function of the endothelium $[24,37,38]$.

We have recorded that an increase in NO has a modest but significant effect in modifying the percentage of typed platelets, which tend to reverse, as previously reported in patients with chronic renal failure at different levels of uraemia [37]. 


\section{Medical Journal of Clinical Trials \& Case Studies}

Recent experiments on animals provide hope for the next clinical use of PEMF. Some authors have shown a positive effect of pulsed electromagnetic field (PEMF) on infarct size and inflammation after cerebral ischemia in mice, other have described that PEMF enhances the phosphorylation of protein kinase B (Akt) and endothelial nitric oxide synthase (eNOS), which may be closely related to attenuated cell apoptosis by increasing the releasing of nitric oxide (NO) and other have described change of HCN1 / HCN2 mRNA expression in peripheral nerve after chronic constriction injury and indicated that PEMF can promote nerve regeneration and could be used for the treatment of chronic ischemia [39-44].

The multi-disciplinary operation, the more times required, besides guaranteeing a higher level of competence in the professional, should not exclude nonconventional techniques. The anti-thrombotic drugs, undoubtedly helpful, have some limitations to date because, when not interacting with the platelet surface receptors, do not affect the interaction of platelets with the endothelium and other blood cells and often are not devoid of side effects. Nevertheless we believe that the prevention of thrombus formation is essential and that anti-platelet drugs should not be abandoned.

The physical source techniques are simple, noninvasive, non-hazardous, are able to produce over short periods interesting clinical results, documented not only with laboratory tests, but also relevant from a clinical point of view. The increase of nitric oxide has shown that the physical sources are able to improve the dysfunctional endothelial and with it an increase in NO in a lasting way. The effects on haemostasis are well documented. It is evident that our results are to be considered, although preliminary, but in each case, individually satisfactory and encouraging.

Moreover, to date, we have no knowledge, if you exclude hyperbaric oxygen therapy, of nonpharmacological techniques and non-invasive ways to act within the microcirculatory system which are repeatable, and that, in cases of altered metabolic states, are capable of inducing beneficial effects. The physical sources may be advantageously used to improve the endothelial function, the microcirculation and tissue perfusion in combination with drugs already in use.

Recently we have shown that the administration of negative charges accelerates the healing of difficult wounds in the lower limbs in diabetic patients and increases the blood concentration of NO [20].

Liani M, et al. Reversibility of Endothelial Dysfunction Induced by Low Frequency of Electromagnetic Field in Patients with Diabetes Mellitus in Dialysis Extracorporeal. Med J Clin Trials Case Stud 2018, 2(5): 000175.

\section{Conclusions}

The antithrombotic drugs prevent the formation of clots or the occlusion of the vessels by the separation of portions of clots. They are therefore irreplaceable to avoid acute ischemic phenomena. Endothelial dysfunction is associated with the totality of chronic diseases and compromises the vitality of tissues altering biological processes while preserving the patency of the vessels. We have shown that, in the treated subjects, the stimulation with biophysical systems induces synthesis of NO and improves some surface platelet receptors. We have not shown that the two phenomena can be correlated with each other but are nevertheless at an endothelium with an improved function. Given the specific functions of antithrombotic drugs and biophysical therapies, we believe that the use of one method does not exclude the other.

\section{References}

1. Hoffmann M, Kujath P, Flemming A, Proß M, Begum N, et al. (2015) Survival of diabetes patients with major amputation is comparable to malignant disease. Diab Vasc Dis Res 12(4): 265-271.

2. Ritz E, Rychlík I, Locatelli F, Halimi S (1999) End-stage renal failure in type 2 diabetes: A medical catastrophe of worldwide dimensions. Am J Kidney Dis 34(5): 795-808.

3. Kainz A, Hronsky M, Stel VS, Jager KJ, Geroldinger A, et al. (2015) Prediction of prevalence of chronic kidney disease in diabetic patients in countries of the European Union up to 2025. Nephrol Dial Transplant Suppl 4: iv113-iv118.

4. Schiller A, Florica Gadalean F, Schiller O, Timar R, Bob F, et al. (2015) Vitamin D Deficiency-Prognostic Marker or Mortality Risk Factor in End Stage Renal Disease Patients with Diabetes Mellitus Treated with Hemodialysis-A Prospective Multicenter Study. PLOS ONE 10(5): e0126586.

5. Jhund PS, McMurray JJ, Chaturvedi N, Brunel P, Desai AS, et al. (2015) Mortality following a cardiovascular or renal event in patients with type 2 diabetes in the ALTITUDE trial. Eur Heart J 36(36): 2463-2469.

6. Arcangeli A, Cosentino F, Cricelli C, Licata G, Marengo M, et al. (2006) Sindrome Metabolica oggi: che cosa 


\section{Medical Journal of Clinical Trials \& Case Studies}

c'è da sapere, che cosa c'è da fare. Italian Journal of Internal Medicine 5(3): 1-27.

7. Michael Brownlee (2005) The Pathobiology of Diabetic Complications. Diabetes 54(6): 1615-1625.

8. Ghiadoni L, Cupisti A, Huang Y, Mattei P, Cardinal H, et al. (2004) Endothelial dysfunction and oxidative stress in chronic renal failure. J Nephrol 17(4): 512519.

9. Di Micco L, Mozzillo GR, Cianciaruso B (2009) Epidemiologia della patologia cardiovascolare nella CKD-MBD. Giornale Italiano di Nefrologia S-49: 3-10.

10. Danielle Davidson, RK Basu, SL Goldstein, LS Chawla (2014) Fluid management in adults and children: core curriculum. American Journal of Kidney Diseases 63(4): 700-712.

11. Chappell D, Westphall M, Jacob M (2009) The impact of the glycocalyx on microcirculatory oxygen distribution in critical illness. Curr Opin Anaesthesiol 22 (2): 155-162.

12. Lin HY, Lin YL (2011) Effects of Low frequency electromagnetic fields on osteoblast proliferation and maturation in an inflammatory environment. Bioelectromagnetics 32: 552-560.

13. Tepper OM, Callaghan MJ, Chang EI, Galiano RD, Bhatt $\mathrm{KA}$, et al. (2004) Electromagnetic fields increase in vitro and in vivo angiogenesis through endothelial release of FGF-2. FASEB J 18(11): 1231-1233.

14. Henry SL, Concannon MJ, Yee GJ (2008) The effect of Magnetic Fields on Wound Healing Experimental Study and Review of the Literature. Eplasty 8: e40.

15. Badal SS, Danesh FR (2012) Strategies to reverse endothelial dysfunction in diabetic nephropathy. The Kidney International 82(11): 1151-1154.

16. Zoja C, Zanchi C, Benigni A (2015) Key pathways in renal disease progression of experimental diabetes. Nephrol Dial Transplant Suppl 4: iv54-iv59.

17. Tabrah F, Hoffmeier M, Gilbert F Jr, Batkin S, Bassett CA (1990) Bone density changes in osteoporosisprone women exposed to pulsed electromagnetic fields (PEMFs). J Bone Miner Res 5(5): 437-442.

18. Lazovic M, Kocic M, Dimitrijevic L, Stankovic I, Spalevic M (2012) Pulsed electromagnetic field

Liani M, et al. Reversibility of Endothelial Dysfunction Induced by Low Frequency of Electromagnetic Field in Patients with Diabetes Mellitus in Dialysis Extracorporeal. Med J Clin Trials Case Stud 2018, 2(5): 000175. during cast immobilitation in postmenopausal women with Colles' fracture. Srp Arh Celok Lek 140(9-10): 619-624.

19. De Lorenzo A, Martinoli R, Carbonelli MG, Monteleone G, Di Lorenzo N, et al. (2004) Resting metabolic rate incremented by pulsating electrostatic field (PESF therapy). Diab Nutr Metab 17(5): 309-312.

20. Liani M, Trabassi E, Cusaro C, Zoppis E, Maduli E Pezzato R, et al. (2014) Effects of a pulsatile electrostatic field on ischemic injury to the diabetic foot: evaluation of refractory ulcers. Primary Care Diabetes 8(3): 244-249.

21. Traikov L, A Ushiyama, G Lawlot, R Sasaki, C Ohkubo (2005) Subcutaneous arteriolar vasomotion changes during and after ELF-EMF exposure in mice in vivo. Environmenthalist 25(2-4): 93-101.

22. Patruno A, Amerio P, Pesce M, Vianale G, Di Luzio S, et al. (2010) Extremely low frequency electromagnetic fields modulate expression of inducible nitric oxide synthase, endothelial nitric oxide synthase and cyclooxygenase- 2 in the human keratinocyte cell line HaCat: potential therapeutic effects in wound healing. Br J Dermatol 162(2): 258-266.

23. Smith TL, Wong-Gibbons D, Maultsby J (2004) Microcirculatory effects of pulsed electromagnetic fields. J Orthop Res 22 (1): 80-84.

24. Di Lullo L, Floccari F, Alberto Santoboni A, Vincenzo Barbera V, Rivera RF, et al. (2013) Progressione delle calcificazioni valvolari cardiache e velocità di progressione del danno renale in pazienti affetti da Malattia Renale Cronica. Journal of Nephrology 26(4): 739-744.

25. VaneJR, Anggard EE, Botting RM (1990) Regolatory functions of the vascular endothelium. $N$ Engl J Med 323(1): 27-36.

26. Amandola G, Terreni V (1995) Analisi chimica strumentale e tecnica. Masson Scuola, pp: 574.

27. Miles AM, Wink DA, Cook JC, Grisham MB (1996) Determination of nitric oxide using fluorescence spectroscopy. Methods in Enzymology 268: 105-120.

28. Atay AE, Akbas H, Tumer C, Sakar MN, Esen B, et al. (2014) The association of endothelial nitric oxide synthase gene G894T polymorphism and serum nitric oxide concentration with microalbuminuria in 


\section{Medical Journal of Clinical Trials \& Case Studies}

patients with gestational diabetes. Clin Nephrol 81(2): 105-111.

29. Drzewosky J, Watala C (2004) Is Aspirin Resistance a Real Problem in People With Type 2 Diabetes? Diabetes Care 27(5): 1245-1246.

30. Takahashi S, Ushida M, Komine R, Shimizu A, Uchida T, et al. (2007) Increased basal platelet activity, plasma adiponectin levels, and diabetes mellitus are associated with poor platelet responsiveness to in vitro effect of aspirin. Thrombosis Research 119(4): 517-524.

31. Watala C, Golanski J, Pluta J, Boncler M, Rozalski M, et al. (2004) Reduced sensitivity of platelets from type 2 diabetic patients to acetylsalicylic acid (aspirin) its relation to metabolic control. Thrombosis Research 113(2): 101-113.

32. Bertolucci AA, Tendera M, Howard G (2011) Metaanalysis of multiple primary prevention trials of cardiovascular event using aspirin. Am J Cardiol 107(12): 1796-1801.

33. Raju N, Sobieraj-Teaque M, Nirsh J, Donnell MO, Eikelboom J (2011) Effect of aspirin on mortality in the primary prevention of cardiovascular disease. Am J Med 124(7): 621-629.

34. Butalia S, Leung AA, Ghali WA, Rabid DM (2011) Aspirin effect on the incidence of major adverse cardiovascular events in patients with diabetes mellitus: a systematic review and meta-analysis. Cardiovascular Diabetol 1: 10-25.

35. Liani R, Trabassi E, Di Marco T, Velussi C, Salvati F, et al. (2010) Dubbi sulla completa efficacia dell'aspirina nella prevenzione della malattia vascolare nel diabete mellito tipo II: studio dei recettori piastrinici di superficie GPIb e GPIIb/IIIa. Atti del XV Congresso Nazionale FADOI, Bologna, pp: 16-19.

36. Bertoluzzo SM, Bollini A, Rasia M, Raynal A (1999) Kinetics model for erythrocyte aggregation. Blood cells, molecules, and disease 25(6): 339-349.
37. Liani M, Salvati F, Golato M, Tresca E (1996) Platelet glycoproteins GPIb and GPIIb/IIIa abnormalities in uremia. Nephron 72(4): 716.

38. Gargiulo G, Labanca F, Lapi D, Oliviero R, Quarto E, et al. (2008) The effects of treatment with pulsating electrostatic fields on cutaneous microvascular flow motion patterns. Atti del 5th Conference if the European Study Group on Cardiovascular Oscillation, pp: 5-7.

39. Pena-Philippides JC, Yang Y, Bragina O, Hagberg S, Nemoto E, et al. (2014) Effect of pulsed electromagnetic field (PEMF) on infarct size and inflammation after cerebral ischemia in mice. Transl Stroke Res 5(4): 491-500.

40. Ma F, Li W, Li X, Tran BH, Suguro R, et al. (2016) Novel protective effects of pulsed electromagnetic field ischemia/reperfusion injury rats. Biosci Rep 36(6): e00420.

41. Liu H, Zhou J, Gu L, Zuo Y (2017) The change of HCN1/HCN2 mRNA expression in peripheral nerve after chronic constriction injury induced neuropathy followed by pulsed electromagnetic field therapy. Oncotarget 8(1): 1110-1116.

42. Genet S, Costolat R, Burger J (2001) The influence of plasma membrane electrostatic properties on the stability of cell ionic composition. Biophys J 81(5): 2442-2457.

43. Shiga T, Imaizumi K, Harada N, Sekiya M (1983) Kinetics of rouleaux formation using TV image analyzer human erythrocytes. Am J Phisiol Heart Circ Phisiol 245(2): H252-258H.

44. Liani M, Trabassi E, Di Luzio R, Tripaldi R, Lattanzio S, et al. (2018) Pulsed Electrostatic Field (PESF) and Patients with Type 2 Diabetes Undergoing Hemodialysis: Endothelial Dysfunction and Altered Hemostasis. Medical Journal of Clinical Trials \& Case Studies 2(3): 1-9. 